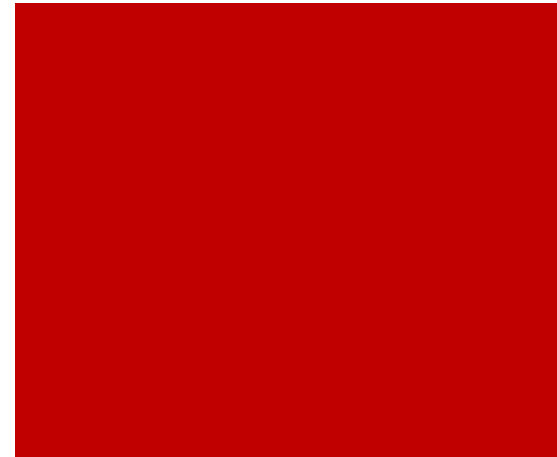

A Revista HISTEDBR On-line publica artigos resultantes de estudos e pesquisas científicas que abordam a educação como

fenômeno social em sua vinculação com a reflexão histórica

Correspondência ao Autor

Nome: Eliane Peres

E-mail: eteperes@gmail.com

Instituição: Universidade

Federal de Minas Gerais, Brasil

Submetido: 10/07/2019

Aprovado: 29/02/2020

Publicado: 09/07/2020

doi> 10.20396/rho.v20i0.8655650 e-Location: e020029

ISSN: 1676-2584

Checagem Distribuído

Antiplágio

Sobre

turnitin' c) (i) (9)
CARTA DE ABC, DE ANTONIO MARIA BARKER (LIVRARIA COMMERCIAL, PELOTAS, 1924)

(1D) Lattes Eliane Peres $^{1}$

\section{RESUMO}

O objetivo principal deste artigo é apresentar e analisar um impresso específico para o ensino inicial da leitura e da escrita: o pequeno livro cujo título é Carta de ABC, de autoria do português Antonio Maria Barker, que foi editado e comercializado pela Livraria Commercial, de Pelotas, Rio Grande do Sul, em 1924. O livreto apresenta o alfabeto, sílabas, palavras e frases (máximas morais) em oito Cartas que, progressiva e paulatinamente, inseriam o aprendiz iniciante na arte da leitura e da escrita, observando a gradação das letras às palavras. Os dados da pesquisa indicam para o uso desse artefato tanto em escolas quanto no âmbito doméstico.

PALAVRAS-CHAVE: Carta de ABC. Barker. Leitura. Escrita. Livraria Commercial. 


\title{
CARTA DE ABC, BY ANTONIO MARIA BARKER (LIVRARIA COMMERCIAL, PELOTAS, 1924)
}

\begin{abstract}
The main goal of this article is to present and analyze a specific printed booklet aimed at teaching reading and writing, entitled Carta de $A B C$, which was written by Portuguese author Antonio Maria Barker. The booklet was published and sold by Livraria Commercial, a publishing house and bookstore from Pelotas, Rio Grande do Sul state, Brazil, in 1924. It presents the alphabet, syllables, words, and phrases (moral maxims) in eight "Cartas" ("Letters"). Progressively and gradually, those texts presented the art of reading and writing to beginner learners, through a sequence from letters to words. Research data indicates this learning artifact was used both in schools and at homes.
\end{abstract}

Keywords: Carta de ABC. Barker. Reading. Writing. Livraria Commercial.

\section{CARTA DE ABC, DE ANTONIO MARIA BARKER (LIVRARIA COMMERCIAL, PELOTAS, 1924)}

\section{Resumen}

El principal objetivo de este artículo es presentar y analizar un impreso singular para la enseñanza de la lectura y de la escritura: el pequeño libro cuyo título es Carta de $A B C$, de autoría del portugués Antonio Maria Barker, que fue editado y comercializado por la librería Livraria Commercial, de la ciudad de Pelotas, Rio Grande do Sul, en 1924. El folleto presenta el abecedario, las sílabas, las palabras y las frases (máximas morales) en ocho cartas que, progresiva y gradualmente, introducían el aprendiz iniciante en el arte de la lectura y la escritura, observando la gradación desde las letras hacia las palabras. Los datos de la pesquisa recomiendan el uso de este artefacto tanto en escuelas como en el ámbito doméstico.

Palabras clave: Carta de ABC. Barker. Lectura. Escritura. Livraria commercial. 


\section{INTRODUÇÃO}

O objetivo principal deste artigo é apresentar e analisar um impresso específico para o ensino inicial da leitura e da escrita: o pequeno livro ${ }^{2}$ cujo título é Carta de $\mathrm{ABC}$, de autoria do português Antonio Maria Barker, que foi editado e comercializado pela Livraria Commercial, da cidade de Pelotas, Rio Grande do Sul, em 1924³.

Tal estudo justifica-se na medida em que, primeiro, as denominadas cartas de ABC foram um dos artefatos - manuscritos ou impressos - mais comumente usados na alfabetização de crianças e adultos em várias partes do mundo Ocidental das sociedades de escrita alfabética, incluindo aí, obviamente, o Brasil ${ }^{4}$; em segundo lugar, o estudo justifica-se também em razão de que Carta de ABC aqui estudada foi publicada, em 1924, pela Livraria Commercial, importante casa editorial pelotense. Procura-se compreender, então, além da natureza do próprio impresso, os sentidos da sua publicação, na década 20 do século XX - momento em que que diferentes cartilhas já estavam disponíveis no mercado didático ${ }^{5}$-, pela referida Livraria de Pelotas.

É preciso enfatizar que o estudo aqui apresentado se insere no campo da história da alfabetização na intersecção com o campo da cultura material escolar. A história da alfabetização tem se constituído como uma importante área de pesquisa no Brasil nos últimos anos, enfatizando, entre outras temáticas, métodos e processos de ensino e de aprendizagem do ler e do escrever, agentes e agências alfabetizadoras, histórias e trajetórias de vida de professoras alfabetizadoras, materiais para alfabetização, com destaque para as cartilhas escolares e outros suportes manuscritos e impressos para o ensino inicial da leitura e da escrita. Assim, destaca-se que a historiografia da alfabetização vem crescendo de forma considerável nas últimas décadas no Brasil. De acordo com Magda Soares (2006, p. 7),

[...] quanto mais problemática é a área no presente, mais se busca recuperar o passado, na tentativa de encontrar, no caminho já trilhado, pegadas que expliquem o presente e assim orientem a solução de problemas e o avanço em direção ao futuro. E a aprendizagem inicial da língua escrita, no contexto escolar, se apresenta, atualmente, como um grande e grave problema que, não é novo, já que temos sido reincidentes em nosso fracasso em alfabetizar crianças.

Se, por um lado, a perspectiva da história da alfabetização baliza esse estudo, por outro, compreende-se que a análise de um livro para o ensino inicial da leitura e da escrita, como o caso aqui em pauta, insere-se também na perspectiva da pesquisa no campo da cultura material escolar entendida como o "[...] conjunto dos artefatos materiais em circulação e uso nas escolas, mediados pela relação pedagógica, que é intrinsecamente humana, revelador da dimensão social." (PERES; SOUZA, 2011, p. 56). Muito embora esse conceito de cultura material refirase mais diretamente à escola, no presente estudo trabalha-se com a hipótese de que Carta de $\mathrm{ABC}$, de Barker, não tenha sido de uso exclusivamente escolar, como, via de regra, era o caso dos abecedários em geral. Contudo, independente do espaço de uso (escolar ou doméstico) sua 
função era servir de suporte de ensino e aprendizagem das primeiras letras, fazendo dele, portanto, um artefato da cultura material instrucional e/ou educacional.

Vinculado a esses campos teórico metodológicos, organizou-se o presente texto em duas seções: na primeira, discute-se o que são cartas $\mathrm{ABC}$ - também denominadas de abecedários e, por vezes, de silabários - e seus usos; na segunda, descreve-se a Carta de ABC, de Antonio Maria Barker e procura-se apresentar algumas possíveis explicações para compreender a sua editoração e comercialização por uma empresa local, qual seja, a Livraria Commercial de Meira \& Cia, de Pelotas, no estado do Rio Grande do Sul.

\section{AS CARTAS DE ABC PARA O ENSINO DA LEITURA E ESCRITA}

Em uma primeira conceituação pode-se considerar, como afirmou Choppin (2009), que abecedário é, desde o século XVI, um pequeno livro impresso. Stephanou e Souza (2016, p. 301) observam que "[...] os abecedários têm uma longa história, remontam mesmo à invenção dos sistemas de escrita e das convenções elaboradas para sustentá-las.” As autoras estabelecem, ainda, baseadas em estudos de autores franceses, a relação entre os abecedários e o uso das letras capitulares nos manuscritos da Idade Média. Segundo elas, "[...] uma espécie de reunião dessas belas letras esboçava a emergência do abecedário como conjunto de letras do alfabeto." (STEPHANOU; SOUZA, 2016, p. 301). Relembrando as inscrições do abc em tapeçarias da Idade Média e as genealogias bordadas das linhagens familiares, as supracitadas autoras enfatizam "[...] os usos sociais e culturais, antes mesmo da adoção escolar dos abecedários como artefatos ligados aos métodos de ensino da leitura e da escrita." (STEPHANOU; SOUZA, 2016, p. 301).

No que tange aos usos dos abecedários como método de aprendizagem para o contexto francês, os registros remontam ao século XV e sua difusão se alarga consideravelmente no século XVIII em diferentes partes do mundo Ocidental ${ }^{6}$.

Vojniak (2014, p. 29) chama a atenção para o fato de que:

Nas primeiras décadas do século XIX [...] a pessoa que se encarregasse da tarefa do ensino da leitura e da escrita, se tivesse condições de não limitar-se a confeccionar de forma manuscrita seus próprios recursos didáticos, além das incipientes cartilhas, poderia dispor de certa variedade de impressos como, por exemplo, as cartas de alfabetos, que eram folhetos organizados, na maioria dos casos, com diversas formas de letras estampadas - capitais, minúsculas, de fôrma (redonda) e cursivas - e frequentemente vinham acompanhadas de algumas apresentações de combinações de sílabas e palavras aparentemente simples ou nomes de pessoas; esse tipo de material apelava mais para o visual do que para o discursivo (textos morais, ideológicos ou informativos) e era impresso em poucas páginas, geralmente "in fólio"; os exemplos de nominação destes materiais são as "Cartas de A B C", as "Cartas de Nome", os "Silabários", os "Murais" e os "Abecedários". 
As denominações cartas, abecedários, silabários, cartinhas e cartilhas, embora tenham especificidades, guardam, entre si, relações. Em um estudo da produção editorial para o ensino da leitura e da escrita no contexto português, Boto (2004, p. 495) indica que:

[...] o termo cartilha constitui um desdobramento da palavra "cartinha" que, por sua vez, era usada - em língua portuguesa - desde o princípio da Idade Moderna, para identificar aqueles textos impressos cujo propósito explícito seria o de ensinar a ler, escrever e contar. Apresentavam usualmente o abecedário, a construção das palavras e suas subdivisões, alguns excertos simples com conteúdos moralizadores, quase sempre precedidos de excertos de orações ou de salmos [...].

A mesma autora considerou, ainda, que:

Naqueles meados do século XIX português - ao que tudo indica - persistia a predominância do uso de abecedários e manuscritos para o ensino da leitura e da escrita, tal como ditava a tradição herdada do século XVIII, naquilo que Rogério Fernandes (1994) identifica como "os caminhos do ABC". (BOTO, 2004, p. 497).

Outro historiador da cultura escrita, Frago (1997, p. 154), refere o termo cartilha como um "cuaderno pequeno, impresso, que contiene lãs letras del alfabeto y los primeiros rudimentos para aprender a ler"; ou seja, tal conceituação pode ser aplicada também para caracterizar as cartas de $\mathrm{ABC}$ e/ou abecedários e silabários.

Choppin (2009, p. 18), referência nos estudos de livro didático, escreve, por sua vez, que:

A cartilla é o nome dado em espanhol (cartilha, em português) aos pequenos livretos que apresentam as letras do alfabeto e os primeiros rudimentos da aprendizagem da leitura, e se difundem muito na Europa, a partir do século XVI. Ela consta de uma simples folha (carta) impressa que, dobrada duas ou três vêzes, forma um caderno in$4^{\circ}$ ou in- $8^{\circ}$, com oito ou dezesseis páginas. Essa palavra teve uma imensa popularização, na Península Ibérica e na América Latina, que, na língua espanhola familiar, as expressões cantar a uno la cartilla e no saber la cartilla (não saber a cartilha em português) significam respectivamente "fazer a lição para alguém" e "ser completamente ignorante"

Contudo, é preciso considerar que,

[...] os termos cartilha e carta guardam uma certa familiaridade entre si e isto reforçaria o entendimento de que não existe diferença alguma entre uma e outra. No entanto, a análise dos documentos tem revelado que, apesar da semelhança constitutiva e da familiaridade etimológica, esses dois artefatos de ensino apresentam traços singulares. (CORRÊA; SILVA, 2008, p. 2).

Assim, de acordo com Corrêa e Silva (2008, p. 2), “[...] é possível dizer que as cartas de abc eram constituídas por abecedário maiúsculo e minúsculo; os silabários compostos com segmentos de uma, duas ou três letras e, por fim, as palavras soltas cujos segmentos silábicos apareciam separados por hífen." 
Carta de $\mathrm{ABC}$, de Antonio Maria Barker, reunia, como se verá a seguir, o alfabeto, sílabas, palavras e frases (máximas morais), constituindo aquilo que alguns autores caracterizam como cartas de $\mathrm{ABC}$ ou abecedário e também como silabário. Como um livreto para o ensino inicial da leitura e da escrita, ele é organizado em oito Cartas que, progressiva e paulatinamente, inseriam o aprendiz iniciante na arte da leitura e da escrita, observando a gradação das letras às palavras.

\section{O LIVRETO CARTA DE ABC, DE BARKER, EDITADA PELA LIVRARIA COMMMERCIAL, DE MEIRA \& CIA, DE PELOTAS, EM 1924}

Inicialmente, sobre o autor de Carta de ABC, Antonio Maria Barker, é possível destacar que ele nasceu em Porto, Portugal, em 1792, e chegou ao Brasil, se estabelecendo no Rio de Janeiro, em 1810, tendo lá falecido, em 1853.

Barker teve uma vasta produção literária, pedagógica e didática. Entre suas obras estão: a) Diálogo ortográfico da língua portuguesa com reflexões e notas sobre as diferentes opiniões dos ortógrafos (1834); b) Diálogo gramatical da língua portuguesa que para inteligência das regras de ortografia contém o que é absolutamente indispensável, e o que apenas se pode ensinar nas escolas (1841); c) Resumo caligráfico ou método abreviado de escrita inglesa, dividido em seis lições (1845); d) Diretório sintético e analítico ou instruções práticas acerca dos compêndios de instrução primária (1853); e) Ortografia, ou Primeira parte da gramática portuguesa em forma de diálogo com reflexões e notas sobre as diferentes opiniões dos ortógrafos (1855); f) Compêndio de civilidade cristã para se ensinar praticamente aos meninos (1858); g) Gramática da língua portuguesa em forma de diálogo, que para inteligência da ortografia contém apenas o que é absolutamente indispensável, e o que apenas se pode ensinar nas escolas (1860); h) Parnaso juvenil ou poesias morais, colecionadas, adaptadas e oferecidas à mocidade (1860); i) Compêndio de doutrina cristã (1862); j) Rudimentos aritméticos ou tabuadas de somar, diminuir, multiplicar e dividir, com as principais regras dos quebrados e decimais (1865); 1) Jogo do ABC para se ensinar, brincando, aos meninos o conhecimento das letras. (BIBLIOTECA DIGITAL DE LITERATURAS DE LÍNGUA PORTUGUESA, 2018).

Ficou conhecido também pela autoria de silabários portugueses, publicados em duas partes, quais sejam: 1) Syllabario portuguez, ou arte completa de ensinar a ler. Primeira parte, em que se tracta das syllabas mais necessarias, etc.; 2) Syllabario portuguez, ou arte completa d'ensinar a ler. Segunda parte. Em que se trata das lições de palavras, expostas em duas columnas: na $1^{\mathrm{a}}$ com os syllabas divididas, na $2^{\mathrm{a}}$ sem divisão alguma. Os dados indicam que o primeiro silabário foi editado pela primeira vez em 1834, no Porto, e posteriormente em 1860, 1861, 1862, no Rio de Janeiro; o segundo silabário foi publicado em 1861, no Rio de Janeiro. (CORPUS DE TEXTES LINGUISTIQUES FONTAMENTAUX, 2019). 
O catálogo da Livraria Garnier, do Rio de Janeiro, anunciava a venda de obras de Antonio Maria Barker, como se pode ver na Figura 1, indicando para a circulação no país de vários de seus livros:

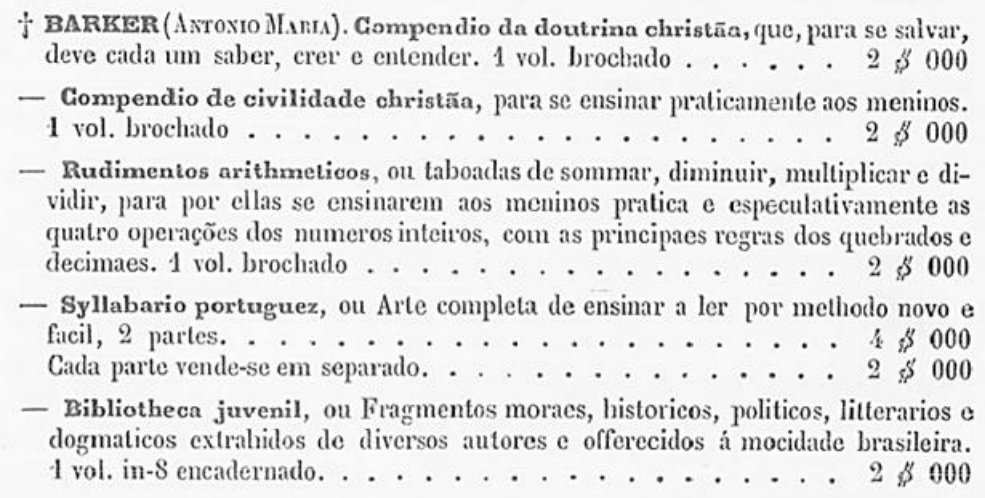
vidir, para por ellas se ensinarem aos meninos pratica e especulativamente as quatro operações dos numeros inteiros, com as principaes regras dos quebrados e decimaes. 1 vol. brochado .............. . . . $2 \$ 000$

- Syllabario portuguez, ou Arte completa de ensinar a ler por methodo novo e facil, 2 partes. .................. $4 \$ 000$ Cada parte vende-se em separado. . . . . . . . . . . . $2 \$ 000$

- Bibliotheca juvenil, ou Fragmentos moraes, historicos, politicos, litterarios e dogmaticos extrahidos de diversos autores e offerecidos á mocidade brasileira. 1 vol. in-S encadernado. . . . . . . . . . . . $2 \$ 800$

Figura 1 - Lista de obras de Antonio Maria Barker à venda Fonte: Catalogo ... (2019, p. 5).

Para o caso do Rio Grande do Sul, há dados sobre a adoção dos silabários de Barker em escolas públicas e privadas, como, por exemplo, no documento de 1880, reproduzido a seguir:

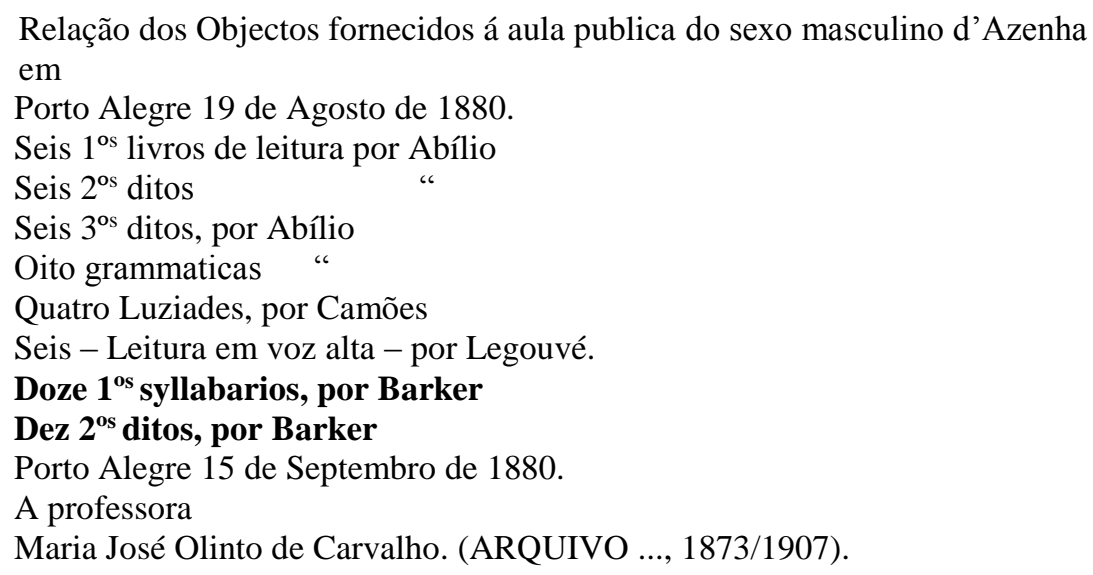

A lista da relação de objetos fornecidos pelo governo à aula pública do sexo masculino da Azenha, registrada no Livro do Inventário, de registro do material fornecido à escola entre 1873 - 1907, revela a circulação e o uso concomitante das cartilhas e dos silabários, nesse caso específico do livro de Abílio César Borges, bastante popular à época, e do Silabário de Barker, além de gramática e livros de leitura. Para a realidade do Rio Grande do Sul é preciso considerar que durante todo século XIX e mesmo ainda durante o século XX, não diferente de outras províncias do país, havia a concomitância do uso de silabários, cartilhas, manuscritos e livros de leitura para o ensino das primeiras letras nas aulas públicas e particulares ${ }^{7}$. 
Outro dado da circulação e adoção de obras didáticas de Antonio Maria Barker no Rio Grande do Sul está na notícia sobre o aproveitamento de alunos de aulas particulares da cidade de Bagé, noticiadas pelo jornal A Federação, em 1886:

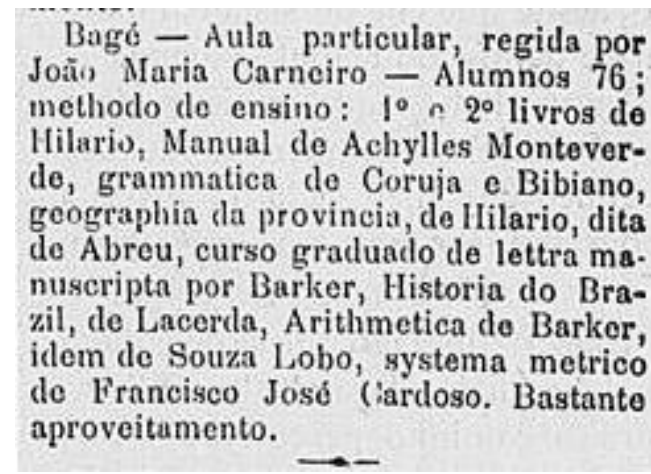

Figura 2 - Notícia do Jornal A Federação Fonte: A Federação (1886, p. 20).

Como se pode observar, há referências ao uso dos silabários, da aritmética, do curso de letra manuscrita de Barker.

Em relação à Carta de $\mathrm{ABC}$, livreto objeto do presente estudo, não foram encontradas referências nas buscas pelas obras do autor. O mais próximo a ele é o título, Jogo do ABC para se ensinar, brincando, aos meninos o conhecimento das letras (s/d), como anteriormente mencionado. Não há, contudo, como afirmar que se trata da mesma obra.

Assim, especificamente em relação à Carta de $\mathrm{ABC}$ destaca-se, primeiramente, a capa que apresenta os dados de autoria e de editoração, como se pode ver na Figura 3:

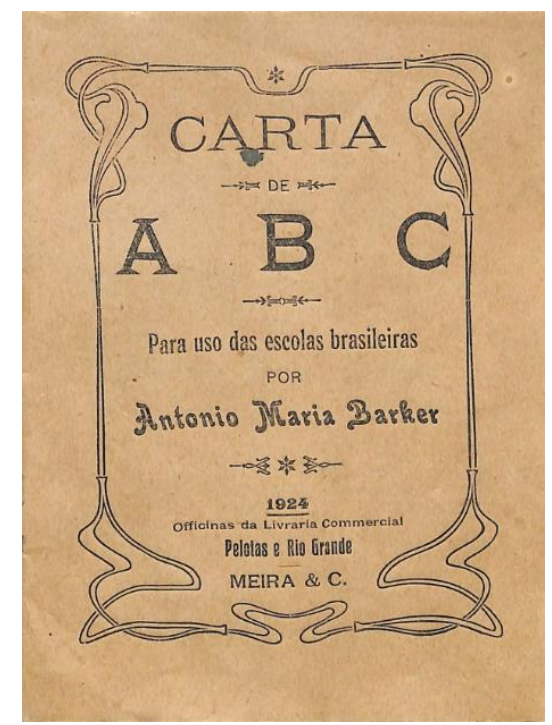

Figura 3 - Capa de Carta de ABC

Fonte: Barker (1924, acervo Hisales). 
O livreto possui 19 páginas e mede $11,3 \mathrm{~cm}$ X 15,1 cm. A primeira lição, apresentada na página 03, é o alfabeto em letras maiúsculas e os números de 1 a 9 mais o cifrão; na sequência, na página 04 , vem o alfabeto minúsculo e os sinas de pontuação; na página 05 , o alfabeto maiúsculo em "letra de mão"; o minúsculo "em letra de mão", mais os números de 1 a 9 e 0 , logo a seguir, que estão na página 06. Tal estrutura indica que as diversas formas de letras capitais, minúsculas, de fôrma e cursiva - eram parte importante de tal gênero, qual seja, cartas de ABC.

No caso específico da Carta de $\mathrm{ABC}$, de Barker, na sequência, na página 07, é apresentada a primeira carta de sílabas, em listas encabeçada pelas vogais e seguidas das sílabas CV. Ao todo são oito cartas (da página 7 à 14, da Primeira Carta de Syllabas à Oitava Carta de Syllabas, sendo que da segunda à oitava são as sílabas CVC).

A primeira carta de palavras está na página 15 (substantivos próprios e comuns) e elas são separadas por hífens. São, ao todo, quatro cartas de palavras (até a página 18$)^{8}$. Finalmente, na última, página 19, está a Carta para Soletrar, com o texto que segue:

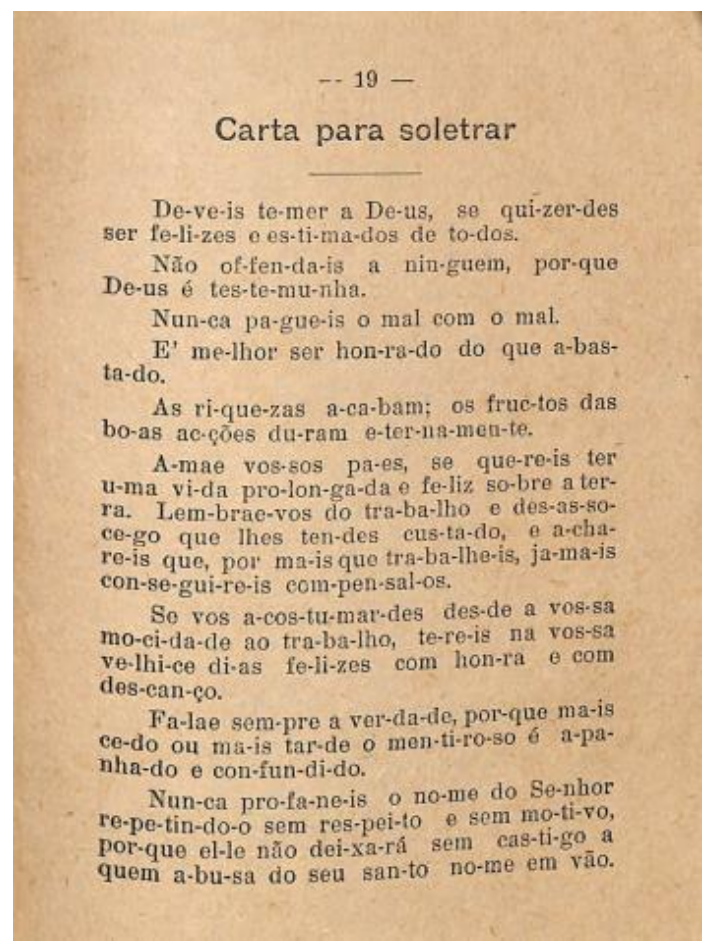

Figura 4 - Página 19 de Carta de ABC

Fonte: Barker (1924, p. 19, acervo Hisales).

Dodds (1967), estudando os livros para ensino da leitura e da escrita no contexto dos Estados Unidos, afirma que desde o período colonial americano e até cerca de 1850, o método de ensinar a leitura inicial permaneceu inalterado. Tratava-se do método alfabético ou da soletração, cujo princípio era ensinar as letras do alfabeto primeiro, depois composições silábicas e, em seguida, palavras. Os primeiros livros eram basicamente silabários. Tal método

\begin{tabular}{l|c|c|c|c|c}
\hline (C) Rev. HISTEDBR On-line & Campinas, SP & v.20 & $1-20$ & e020029 & 2020 \\
\hline
\end{tabular}


presente nesses livros, os silabários, era, também, segundo o autor, chamado de método alfabético de abordagem oral para a leitura, porque as letras, sílabas e palavras em ensinadas em sequências repetidas em voz alta.

A leitura oral e a repetição eram, por excelência, as práticas de ensino da leitura. Contudo, segundo Dodds (1967), um dos maiores problemas com este método sintético-oral eram as letras mudas, as letras com mais de um som e os grupos de letras que representam um único som, ou seja, as irregularidades da língua inglesa criaram problemas para as crianças aprenderem a ler por esse método. Assim, várias técnicas foram utilizadas nos primeiros silabários para ajudar os aprendizes a superarem essas dificuldades e, de acordo com o autor supracitado, um exame destes livros revela algumas dessas estratégias, tais como as marcas diacríticas, as letras impressas em larguras diferenciadas ou com linhas diagonais atravessadas e o emprego de personagens inventados. (DODDS, 1967).

Para o caso de Carta de ABC, de Barker, pode-se perceber que o recurso usado foi o hífen. Marcador das sílabas e, portanto, da leitura - especialmente em voz alta, conhecida como 'cantar as letras' -, o hífen tem, nessa proposta gráfica-pedagógica, uma função importante usada desde a primeira carta de palavras, como se pode ver a seguir na Figura 5, bem como na Figura 4 anteriormente reproduzida, da última carta, chamada "Carta para Soletrar", com as frases, máximas morais acerca da riqueza, do trabalho, da honra, da verdade, do respeito à Deus e à família ${ }^{9}$.



Figura 5 - Páginas 14 e 15 de Carta de ABC

Fonte: Barker (1924, p. 14-15, acervo Hisales).

Compreender o contexto de uso das cartas $\mathrm{ABC}$ na sua relação com o método da soletração é fundamental uma vez que:

\begin{tabular}{l|l|l|l|l|l}
\hline (C) Rev. HISTEDBR On-line & Campinas, SP & v.20 & $1-20$ & $\mathrm{e} 020029$ & 2020 \\
\hline
\end{tabular}


[...] até quase o final do século XIX, parece que só há um caminho para aprender a ler: a soletração, e não há um método complicado que precise ser dominado. Aprendemse os nomes das letras do alfabeto, reconhece-se cada letra fora da ordem, soletra-se seu nome, decoram-se alguns quadros de sílabas e depois se tenta redescobri-las em palavras ou textos. Nas palavras e nos textos, há uma separação por hifens ou espaços que vão guiando a oralidade. Podemos supor que uma pessoa que tenha aprendido por esse procedimento na escola pode transmitir essa "tecnologia de uso" para outros, em espaços escolares e não escolares. Repetir sempre os mesmos procedimentos pode dar uma ideia de estabilidade e simplicidade, incentivando leitores a utilizar, de forma mais autônoma, esse tipo de impresso. Talvez seja por isso que esse material se prolonga para além do tempo e do espaço da escola. (FRADE, 2010, p. 276).

Assim, ao se trabalhar com os livros de iniciação à leitura é fundamental refletir acerca da relação do suporte e suas características gráfico-pedagógicas com o método de ensino. Nesse sentido, é preciso considerar que:

[...] ainda que diferentes em suas formas de produção e divulgação, nem as remotas 'cartas do ABC', a que se seguiram as 'cartas de sílabas', nem as cartilhas - das mais antigas às atuais - conseguiram escapar às discussões, envolvendo, essencialmente, a questão do método de alfabetização. (DIETZCH, 1990, p. 36).

Para além do artefato em si, da sua materialidade, da autoria e do método de ensino, uma das perguntas que se impôs neste estudo foi a seguinte: por que em 1924 a Livraria Commercial de Pelotas ainda editou a Carta de $\mathrm{ABC}^{10}$ ? Quem seria o público "consumidor" desse artefato? Em que medida ainda nos anos 20 do século XX um artefato como esse, cartas de ABC, teria circulação e uso, especialmente nas escolas brasileiras, conforme anunciado desde a capa? E mais especificamente, nas escolas gaúchas? Haveria outros usos desse livreto, que não o escolar? Alguns autores que já se ocuparam do estudo desse artefato ou mencionam sua existência (HÉBRARD, 2002; CHARTIER, 2004; FRADE, 2010), indicam seu uso em âmbito doméstico, por exemplo. Stephanou e Souza (2016, p. 307) enfatizam que os "[...] abecedários constituem artefatos que possuem uma função didática para o exercício inicial da leitura, não exclusivamente na escola." Assim, não seria hipótese infundada considerar que a Livraria Commercial, ao imprimir e comercializar Carta de ABC, de Barker, tivesse em vista, além dos estudantes das escolas brasileiras, famílias interessadas em adquirir este tipo de material impresso para a iniciação à leitura em âmbito doméstico.

Há que considerar, também, nessa hipótese, que esse era um tipo de material que estava disponível à venda desde o século XIX, no comércio das cidades, especialmente em livrarias e tipografias, como se pode ver pelo anúncio a seguir, localizado no Jornal O Conciliador, cujo redator responsável era o jornalista e escritor José Antonio do Valle Caldre e Fião: ANNUNCIOS. CARTAS DE ABC: Em porção e a varejo: vendem-se na typographia de Mello. Aos Srs. Negociantes se vendem pelo preço do Rio de Janeiro. (O CONCILIADOR, 1858, p. $4)$.

Embora o anúncio não especifique a autoria, a editoração (tipografia, livraria ou editora) ou mesmo os tipos das cartas de $\mathrm{ABC}$, a simples menção da venda, à porção ou à varejo, é um

\begin{tabular}{l|l|l|l|l|l} 
(C) Rev. HISTEDBR On-line & Campinas, SP & v.20 & $1-20$ & $\mathrm{e} 020029$ & 2020 \\
\hline
\end{tabular}


dado importante para refletir acerca da circulação desse material, tanto nas escolas públicas e privadas, quanto no espaço doméstico ao longo do século XIX e do século XX. A possibilidade de comprar somente um exemplar ou uma quantidade maior deles, é um indício de usos diferenciados do mesmo artefato.

O Jornal Diário de Notícias, de Porto Alegre, reproduziu, em 1965, um artigo do jornalista e político nordestino José Augusto de Bezerra de Medeiros ${ }^{11}$, no qual ele faz referência ao seu processo de aprendizagem da leitura. Nascido em Caicó, RN, em 1884, Bezerra de Medeiros escreveu que:

Aos cinco anos de idade, em 1889, iniciei a minha aprendizagem escolar. Foi minha mãe que me pôs nas mãos a carta de A.B.C., de Laudelino Rocha. O que é certo é que, por volta de 1892, eu já lia correntemente e lia bem. [...]. (DIÁRIO DE NOTÍCIAS, 1965, p. 13).

Esses dados são apresentados para corroborar a ideia de que as cartas de $\mathrm{ABC}$, nos séculos XIX e XX, tinham uma circulação para além do espaço escolar e de que, portanto, a Livraria Commercial possivelmente teria um público consumidor alvo, além das escolas e dos professores, ao editar Carta de $\mathrm{ABC}$, de Barker: pais, mães, preceptores, filantropos, professores particulares, etc., poderiam estar entre o público que comprava esse tipo de material.

É preciso considerar que havia, ainda, uma parcela bastante significativa da população para alfabetizar no Rio Grande do Sul no período em questão ${ }^{12}$. Os dados gerais sobre o analfabetismo no Brasil e na Província/Estado permitem refletir acerca da necessidade de materiais simples e baratos que pudessem contribuir nessa tarefa de alfabetizar a população. Assim, é preciso observar a problemática secular do analfabetismo no Brasil (FERRARO, 1985) para compreender o mercado das cartas de $\mathrm{ABC}$ ainda nas primeiras décadas do século XX.

Segundo Ferraro e Kreidlow (2004), considerando o Censo de 1872, a taxa de analfabetismo do país era de $82,3 \%$ para as pessoas de 5 anos ou mais, situação que se manteve inalterada pelo menos até o segundo Censo, realizado em 1890 (82,6\%), já no início da República, como demostraram os autores citados. Para o caso do Rio Grande do Sul, ainda segundo o estudo de Ferraro e Kreidlow (2004), as taxas de analfabetismo eram de 76,8\% em 1872 para 69,7\% em $1890^{13}$. Embora em declínio, chegou-se aos anos de 1920, período da publicação de Carta de ABC pela Livraria Commercial, com uma taxa de analfabetismo, no Rio Grande do Sul, de 53,8\% da população com cinco anos e mais (FERRARO, 1985) ${ }^{14}$. O que se quer demostrar, de fato, é que o contexto também explica, obviamente, a edição do referido livreto. Se havia contingentes populacionais a serem alfabetizados - para o caso do Rio Grande do Sul, pouco mais da metade da população com cinco anos e mais era analfabeta segundo dados do Censo de 1920 -, havia um potencial mercado consumidor de artefatos para o ensino das primeiras letras.

Sobre a Livraria Commercial, Arriada (2012) salienta que ela foi criada em Pelotas no ano de 1885 e sua razão social era Souza Lima \& Meira. No ano de 1900, Francisco Meira

\begin{tabular}{l|l|l|l|l|l} 
(C) Rev. HISTEDBR On-line & Campinas, SP & v.20 & $1-20$ & $\mathrm{e} 020029$ & 2020 \\
\hline
\end{tabular}


tornou-se seu único proprietário. A sede, localizada em Pelotas, funcionou na Rua Andrades Neves, nos números 604, 606, 608. A filial, por sua vez, funcionou na Rua Marechal Floriano, $\mathrm{n}^{\circ}$ 217, na cidade de Rio Grande, próxima à Pelotas. Ambas as lojas estavam, portanto, localizadas em áreas centrais das cidades. (ARRIADA, 2012, p. 14-15).

O autor indica ainda que, entre as obras editadas pela Livraria Commercial, algumas eram de caráter religioso, entre elas: a) Primeiro Lustro da Diocese de Pelotas (1911-1916); b) Terezinha do Menino Jesus: sua vida, seu espírito (Devocionário, 1924); e outras eram literárias e didáticas, tais como: a) Elementos de Botânica, coordenados pelo Dr. Francisco J. R. de Araújo (1905); b) Livre de Lectures pour la première année avec des explications en portugais et un supplément d'une grammaire française par G.G10 (1921, com $2^{\circ}$ edição ampliada em 1923). Sabe-se que Pelotas, entre a segunda metade do século XIX e início do século XX, foi um centro editorial importante e reunia já um público leitor significativo. (ARRIADA, 2012; GONÇALVES, 2010). A Livraria Commercial, de Meira \& Cia, foi, nesse contexto, uma das importantes casas de editoração pelotense e de venda de material para o ensino, bem como de leitura em geral.

O autor supracitado encontrou, ainda, um anúncio no Álbum de Pelotas, de 1922, que revela que a Livraria Commercial era "[...] especialidade em livros em branco, cadernos, cadernetas, livros para borradores, costaneiras [...] empregamos material de primeira ordem e o maior cuidado na fabricação.” (ARRIADA, 2012, p. 14-15). Da mesma forma, na contracapa de Carta de ABC pode-se ler:

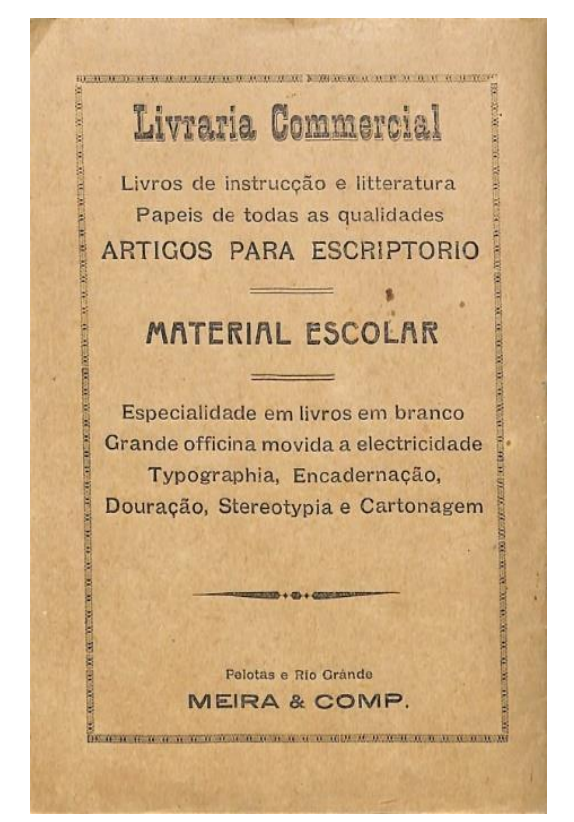

Figura 6 - Contracapa de Carta de ABC Fonte: Barker (1924, acervo Hisales). 
É preciso relembrar que as livrarias, nesse período, eram empresas que, além de comercializar livros, vendiam materiais variados e prestavam diversos serviços, entre eles os tipográficos. Mais do que isso, funcionavam também como editora, caso da Livraria Commercial. Certamente a publicação de Carta de ABC, de Barker, estava de acordo com a tradição editorial da referida Livraria.

Hébrard (2002, p. 15) afirmou que, para o caso francês, a publicação de abecedários era uma tradição dos impressores. Mas, diferentemente daquilo que o autor identificou na França, qual seja, de que "[...] o abecedário situa os impressores do lado de uma tradição editorial que se apoia nas obras sem autoria." (HÉBRARD, 2002, p. 15), para o caso da Livraria Commercial, o abecedário publicado era uma obra com autoria e, mais ainda, de uma autoria qualificada. Antonio Maria Barker era, no contexto da produção didática, um autor reconhecido desde o século XIX e isso talvez tornasse a obra ainda mais vendável, uma vez que é preciso considerar que os livros didáticos são também produtos comercializáveis, ou seja, uma mercadoria, “[...] resultado de uma produção para o mercado." (MUNAKATA,1997, p. 18). Assim, ao que tudo indica, a região de Pelotas, em específico, e o Rio Grande do Sul, de modo geral, nas primeiras décadas do século XX, eram um mercado propício para tal publicação.

\section{CONSIDERAÇÕES FINAIS}

Ao finalizar o estudo, uma das considerações possíveis de fazer é a de que mesmo com o advento da produção e da publicação de diferentes cartilhas para o ensino da leitura e da escrita no século XX, cartas de $\mathrm{ABC}$ continuaram a ser publicadas e comercializadas no Brasil. Podese concluir, assim, que esses diferentes artefatos coexistiram no espaço escolar no referido período. Além disso, trabalha-se com a ideia de que cartas de ABC circularam também em espaços domésticos. Isso ajuda a explicar a edição da Livraria Commercial, de Pelotas, do livreto de Barker, nos anos 20 do século XX.

Na perspectiva da história da alfabetização, por um lado, pode-se afirmar que estudos de artefatos produzidos, comercializados e usados para o ensino inicial da leitura e da escrita, como o caso de Cartas de $\mathrm{ABC}$, são aliados na compreensão dos projetos e práticas específicas adotadas por uma nação para alfabetizar sua população. Não por acaso, ainda na década de 20 do século XIX uma Livraria de renome como a Commercial de Pelotas edita, com selo próprio, Carta de ABC, de Antonio Maria Barker. Havia, portanto, público que comprava tal artefato, indicando sua necessidade no contexto em questão. Os dados sobre os índices de analfabetismo no Rio Grande do Sul reforçam essa hipótese.

Por outro lado, na tradição do campo de estudos da cultura material escolar, é imperativo, como alertou Souza (2007, p. 169), compreender “[...] a relação humana com o mundo material." Nesse sentido é que procurou-se refletir, mesmo que ainda de forma insuficiente, em plausíveis interesses de quem editou Carta de $\mathrm{ABC}$, no caso a Livraria 
Commercial, de Pelotas, e nos possíveis "consumidores" ou "usuários" desse artefato: seriam famílias pelotenses, de posse e dinheiro, que compravam o livreto para o ensino doméstico? Ou ao contrário, seria um material de baixo custo comprado pelas pessoas de poucas posses financeiras? Era adquirido por famílias que moravam em regiões distantes dos grandes centros e, quiçá, longe de escolas? Por professores e professoras que buscavam contribuições didáticas ao ensino escolar? Por proprietários e docentes de escolas e aulas privadas? Por governos das municipalidades da região em que foi editado? Essas são hipóteses possíveis, mas, infelizmente, não há dados de uso desse livreto, exceto alguns indícios. $\mathrm{O}$ fato de o exemplar com o qual se trabalhou ter sido localizado, no século XXI, em uma fazenda no interior de um município próximo à cidade de Pelotas, não é uma informação que possa ser desconsiderada no estudo realizado e nas hipóteses levantadas. A localização de tal material pode ser mais um indicador de seu possível uso, qual seja, por pessoas residentes em zonas distantes dos grandes centros urbanos e, portanto, escolares.

Por fim, ainda nesse campo de estudos, é preciso relembrar que, em se tratando de artefatos e objetos da cultura material escolar e instrucional, trabalha-se com a " [...] dificuldade em identificar o que são, para que servem, e como eram utilizados, principalmente por alguns deles não pertencerem ao nosso universo cultural atual." (VEIGA, 2000, p. 6). No caso de Carta de $\mathrm{ABC}$, de Antonio Maria Barker, o próprio artefato oferece elementos para compreender o que era e para que servia, ou seja, um livreto, de uso relativamente simples e fácil ${ }^{15}$, para a iniciação à aprendizagem do alfabeto, à aprendizagem da leitura e da escrita. Como e por quem foi utilizado são dados que talvez a história da alfabetização não poderá recuperar, pela possível ausência de registros de quem efetivamente o utilizou. Isso, contudo, não diminui a importância de estudos dessa natureza e a necessidade de continuar a fazê-los, uma vez que se compreende que fazer história da alfabetização envolve a reconstrução histórica dos sentidos do que é se tornar alfabetizado, da identificação de como e onde as populações foram alfabetizadas, quais artefatos eram usados no ensino inicial da leitura e da escrita, entre outros aspectos. O estudo aqui apresentado insere-se nessa tradição de pesquisa. Identificando e conhecendo os artefatos produzidos para o ensino das primeiras letras, pode-se inferir aspectos do contexto do texto, uma vez que, como afirmou Luke (1988, p. 15), as pesquisas sobre história da alfabetização devem ser feitas "[...] com base nos existentes artefatos textuais." Foi isso que se procurou fazer com o caso de Carta de ABC, de Antonio Maria Barker, editado pela Livraria do Commercial de Pelotas, Rio Grande do Sul, em 1924. O texto, nesse caso, é indicador do contexto.

\section{REFERÊNCIAS}

A FEDERAÇÃO. Orgam do Partido Republicano. Porto Alegre, 12 de fevereiro de 1886, anno III, n. 35, p. 2. Hemeroteca Digital da Biblioteca Nacional. Disponível em: http://bndigital.bn.gov.br/hemeroteca-digital/. Acesso em: 29 jan. 2019. 
ARRIADA, E. Livrarias e editoras no Rio Grande do Sul: o campo editorial do livro didático. In: REUNIÃO ANUAL DA ANPED, 35., 2012, Porto de Galinhas, PE. Anais [...]. Rio de Janeiro: ANPED, 2012. p. 1-17. v. 01.

ARQUIVO HISTÓRICO DO RIO GRANDE DO SUL (AHRS). Livro do Inventario, 1873. Livro de registro do material fornecido à escola da Azenha. 1873/1907.

BARKER, A. M. Carta de ABC. Para uso das escolas brasileiras. Pelotas e Rio Grande: Livraria Commercial, Meira \& Cia, 1924.

BIBLIOTECA DIGITAL DE LITERATURAS DE LÍNGUA PORTUGUESA. Antonio Maria Barker. Disponível em:

https://www.literaturabrasileira.ufsc.br/busca/simples/?termo=\%22ANTONIO+MARIA+BA RKER\%22\&forma_busca=2. Acesso em: 11 nov. 2018.

BOTO, C. Aprender a ler entre cartilhas: civilidade, civilização e civismo pelas lentes do livro didático. Educação e Pesquisa. São Paulo, v. 30, n. 3, p. 493-511, set./dez. 2004.

CATALOGO DA LIVRARIA DE B. L. GARNIER, Rio de Janeiro, n²3, p. 5. Disponível em:

http://www.circulacaodosimpressos.iel.unicamp.br/arquivos/catalogosLivreiros/RiodeJaneiro/ Catalogos_Garnier/2_Catalogo_da_livraria_de_B_L_Garnier_n_23. Acesso em: 13 abr. 2019.

CHARTIER, A. M. Des abécédaires aux méthodes de lecture: gènese du manuel moderne avant les lois Ferry. Mimeo. 2004. 37 p.

CHARTIER, R. A aventura do livro do leitor ao navegador. São Paulo: Unesp, 1998.

CHOPPIN, A. O manual escolar: uma falsa evidência histórica. História da Educação, Pelotas: ASPHE, v. 13, n. 27, p. 9-75, jan./abr., 2009.

CORRÊAA, C. H. A.; SILVA, L. L. M. da. Cartas de ABC e cartilhas escolares: alfabetização nas escolas amazonenses (1850-1900). CONGRESSO BRASILEIRO DE HISTÓRIA DA EDUCAÇÃO, 5., 2008, Aracaju, SE. Anais [...]. Aracaju, SE: O ensino e a História da Educação, 2008. Disponível em: http://sbhe.org.br/novo/congressos/cbhe5/pdf/442.pdf. Acesso em: 11 nov. 2018.

CORPUS DE TEXTES LINGUISTIQUES FONTAMENTAUX. Barker, António Maria. Biographie de l'auteur. Disponível em http://ctlf.ens-lyon.fr/n_fiche.asp?num=3366. Acesso em: 04 abr. 2019.

DIÁRIO DE NOTÍCIAS, Porto Alegre, 12 de setembro de 1965. Ano XLI, N. 160, p. 13. Hemeroteca Digital da Biblioteca Nacional. Disponível em: http://bndigital.bn.gov.br/hemeroteca-digital/. Acesso em: 29 jan. 2019.

DIETZCH, M. J. M. Cartilhas: um mundo de personagens sem texto e sem história. Cadernos de Pesquisa, n. 75, p. 35-44, nov.1990.

\begin{tabular}{l|l|l|l|l|l} 
(C) Rev. HISTEDBR On-line & Campinas, SP & v.20 & $1-20$ & $\mathrm{e} 020029$ & 2020 \\
\hline
\end{tabular}


DODDS, W. J. Highlights from the History of Reading Instruction. The Reading Teacher, v. 21, n. 3, p. 274-280, dec. 1967. Instructional Practices. Published by: International Literacy Association and Wiley. Disponível em: https://www.jstor.org/stable/20195913. Acesso em: 28 nov. 2018. 19:22 UTC.

FERRARO, A. R. Analfabetismo no Brasil: tendência secular e avanços recentes. Resultados preliminares. Cadernos de Pesquisa, São Paulo, v. 52, n. 52, p. 25-33, 1985. (Fundação Carlos Chagas. Impresso).

FERRARO, A. R.; KREIDLOW, D. Analfabetismo no Brasil: configuração e gênese das desigualdades regionais. Educação e Realidade, Porto Alegre, v. 29, n. 2, p. 179-200, 2004.

FRADE, I. C. A. da S. Uma genealogia dos impressos para o ensino da escrita no século 19. Revista Brasileira de História da Educação, n. 44, p. 264-281, 2010.

FRAGO, A. V. Aprender a leer em el Antigo Régimen: cartillas, silabários y catones. In: ESCOLANO BENITO, A. (dir.). Historia ilustrada del libro escolar en España. Del Antiguo Régimen a la Segunda República. Madrid: Fundación Germán Sánchez Ruipérez, 1997.

GONÇALVES, R. B. Livros e leitura na cidade de Pelotas no final do século XIX: um estudo através dos jornais pelotenses (1875-1900). 2010. $235 \mathrm{f}$. Tese (Doutorado em Educação) -Universidade Federal de Pelotas, Pelotas, 2010.

HÉBRARD, J. Os livros escolares da Bibliothèque Bleue: arcaísmo ou modernidade? Revista Brasileira de História da Educação, n. 4, p. 10-45, 2002.

LUKE, A. Literacy, Textbooks and Ideology: postwar literacy instruction and the mythology of Dick and Jane. Philadelphia: The Falmer Press, 1988.

MUNAKATA, K. Produzindo livros didáticos e paradidáticos. 218 f. Tese (Doutorado em História e Filosofia da Educação) - Pontifícia Universidade Católica de São Paulo, São Paulo, 1997.

O CONCILIADOR. Folha Politica e Miscellanica, Porto Alegre, 2 de dezembro de 1858, anno 1, n. 11, p. 4. Hemeroteca Digital da Biblioteca Nacional. Disponível em http://bndigital.bn.gov.br/hemeroteca-digital/. Acesso em: 29 jan. 2019.

OLIVEIRA, R. A. V. de S. "Recolhendo os cacos": a trajetória de José Augusto Bezerra de Medeiros como construtor de uma escola modelo para o trabalhador (1915-1923). SIMPOSIO NACIONAL DE HISTÓRIA, 29., 2017, Brasília. Anais [...]. Brasília: UnB, 2017. Disponível em: https://www.snh2017.anpuh.org/resources/anais/54/1502846710_ARQUIVO_TextoAnaisdaANPUH2017.pdf. Acesso em: 06 abr. 2019.

PERES, E. Templo de Luz: os cursos noturnos masculinos de instrução primária da Biblioteca Pública Pelotense, 1875-1915. 1995. 137 f. Dissertação (Mestrado em Educação) Faculdade de Educação, Universidade Federal do Rio Grande do Sul, Porto Alegre, 1995.

\begin{tabular}{l|l|l|l|l|l} 
(C) Rev. HISTEDBR On-line & Campinas, SP & v.20 & $1-20$ & $\mathrm{e} 020029$ & 2020 \\
\hline
\end{tabular}


PERES, E.; SOUZA, G. de. Aspectos teórico-metodológicos da pesquisa sobre cultura material escolar (im)possibilidades de investigação. In: CASTRO, C. A. (org.). Cultura Material Escolar: a escola e seus artefatos (MA, SP, PR, SC e RS, 1870-1925). 1. ed. São Luís: EDUFMA: Café \& Lápis, 2011. p. 43-68. v. 1.

PERES, E.; MICHEL, C. B. Circulação e fornecimento de livros escolares no Rio Grande do Sul no final do século XIX e início do século XX (1873-1921). In: PERES, E.; RAMIL, C. de A. (org.). Produção e circulação de livros didáticos no Rio Grande do Sul nos séculos XIX e XX. Curitiba: Appris, 2018.

STEPHANOU, M.; SOUZA, M. V. P. Contribuições para uma história dos métodos didáticos de alfabetização: os abecedários em cartilhas escolares (1919- 1965). SEMINÁRIO INTERNACIONAL SOBRE A HISTÓRIA DO ENSINO DA LEITURA E DA ESCRITA, 2., 2013, Belo Horizonte. Anais [...]. Belo Horizonte: Sihele/UFMG, 2013.

STEPHANOU M.; SOUZA, M. V. P. Abecedários em circulação: entre dicionários, impressos e cartilhas escolares. História da Educação, ASPHE: Porto Alegre v. 20, n. 50, p. 297-325, set./dez., 2016.

SOARES, M. Apresentação. In: FRADE, I. C. A. da. S.; MACIEL, F. I. P. (org.). História da Alfabetização: produção, difusão e circulação de livros (MG/RS/MT - Séc. XIX e XX). Belo Horizonte: UFMG/FaE, 2006.

SOUZA, M. S. P. Abecedários, Brasil: contribuições à história dos impressos e sua circulação nos anos 1936 a 1984. Porto Alegre: Ufrgs, 2015. 152f. Dissertação (Mestrado em Educação) - Faculdade de Educação, Universidade Federal do Rio Grande do Sul.

SOUZA, R. F.de. História da cultura material escolar: um balanço inicial. In: BENCOSTTA, M. L. (org.). Culturas escolares, saberes e práticas educativas: itinerários históricos. São Paulo: Cortez, 2007. p. 163-189.

VEIGA, C. G. Cultura material escolar no século XIX, Minas Gerais. In: I CONGRESSO BRASILEIRO DE HISTÓRIA DA EDUCAÇÃO, 1., 2000, Rio de Janeiro. Anais [...]. Rio de Janeiro: UFRJ, 2000. Disponível em:

http://www.sbhe.org.br/novo/congressos/cbhe1/anais/040_cynthia.pdf. Acesso em: 10 dez. 2018.

VOJNIAK, F. O Império das primeiras letras: epítome de uma história de cartilhas de alfabetização no século XIX. Revista Educação e Políticas em Debate, v. 3, n. 1, p. 23-37, jan./jul. 2014. 


\section{Notas}

${ }^{1}$ Doutorado em Educação pela Universidade Federal de Minas Gerais (UFMG). Professora títular na Universidade Federal de Pelotas (UFPEL).

${ }^{2}$ Trata-se de um livro e não de cartas soltas, em razão do formato, qual seja, a de códice, entendido como uma coleção de folhas amarradas ou coladas umas às outras (CHARTIER, 1998), muito embora seja pequeno em

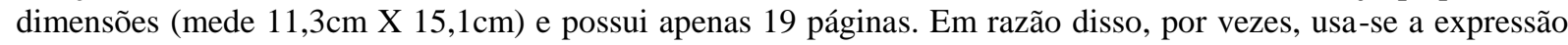
livreto, remetendo ao tamanho e ao número de páginas desse artefato.

${ }^{3}$ Frade $(2010$, p. 266), referindo aos abecedários afirma que "infelizmente, por não terem sido conservados, muitos desses materiais não podem ser analisados diretamente, e é necessário buscar indícios sobre como eles se apresentavam materialmente e sobre alguns significados dessa materialidade no manuseio e uso escolares". Tal afirmativa corrobora a importância do estudo aqui apresentado. O exemplar com o qual trabalhamos foi localizado em uma fazenda no interior do município de São Lourenço do Sul, RS, cidade próxima à Pelotas, RS, e atualmente está sob a guarda do Hisales (História da Alfabetização, Leitura, escrita e dos Livros Escolares), centro de memória e de pesquisa ligado à Faculdade de Educação da Universidade Federal de Pelotas, RS.

${ }^{4}$ Ver para isso, entre outros, Hebrard (2002); Chartier (2004); Chopin (2009); Correa e Silva (2008); Frade (2010); Souza (2015); Stephanou e Souza (2013; 2016).

${ }^{5}$ É preciso considerar, entre outras coisas, que "no caso das cartilhas, elas reuniriam não apenas os elementos presentes nas cartas de abc (abecedário, silabário e palavras), mas também, máximas morais, orações, noções rudimentares de aritmética. Mais abrangentes que as cartas de abc, as cartilhas parecem servir para um uso mais prolongado" (CORRÊA; SILVA, 2008, p. 3).

${ }^{6}$ Ver, entre outros, Hébrard (2002); Chartier (2004); Choppin (2009); Frade (2010); Stephanou \& Souza (2016).

${ }^{7}$ Para saber mais sobre isso ver Peres e Michel (2018).

${ }^{8}$ De forma mais específica, as cartas são: Na primeira carta (p. 7) são apresentadas as sílabas simples (ba, be, bi, bo, bu, por exemplo); na segunda carta (p. 8), todas as sílabas acompanhadas da vogal i (fai, fei, foi, fui, por exemplo); na terceira carta (p. 9), todas as sílabas acompanhadas de l (pal, pel, pil, pol, pul, por exemplo); na quarta carta (p. 10), todas as sílabas acompanhadas de n (san, sem, sin, son, sun, por exemplo); na quinta carta (p. 11), todas as sílabas acompanhadas de r (rar, rer, rir, ror, rur, por exemplo); na sexta carta (p. 12), todas as sílabas acompanhadas de s (mas, mes, mis, mos, mus, por exemplo); na sétima carta (p. 13), as sílabas com encontros consonantais com le com r (gla, gel, gli, glo, glu, por exemplo e tra, ter, tri, tro, tru) e sílabas com n e s (bran, por exemplo e tras, três, tris, tros, trus, por exemplo); e na oitava carta (p. 14), sílabas com ão, ch, lh, nh, ph, th. A primeira carta de palavras é composta por palavras com duas sílabas (p. 15); a segunda de palavras com três sílabas (p. 16); a terceira com palavras com quatro sílabas (p. 17); a quarta com palavras com cinco sílabas (p. 18). Nesse último caso, há duas colunas com as mesmas palavras: na primeira, elas estão separadas por hífen como nas outras páginas/cartas e na segunda estão sem hífen, indicando, possivelmente, que nessa etapa do processo de aprendizagem havia a expectativa de que o aprendiz já pudesse ler as palavras inteiras, sem soletração.

${ }^{9}$ A relação entre ensino das primeiras letras e doutrinação religiosa nos materiais didáticos atravessou séculos na história da educação de diferentes países. Para o caso da França do século XVII, por exemplo, Hébrard (2002, p. 12), estudando os livros da chamada "Bibliotèque Bleue", produzidos pelos impressores de Troyes, identificou que "entre os livros de uso escolar, o abecedário é aquele que, certamente, representa a maior promessa de venda. Sob o nome de Instruções Cristãs - é assim que são chamados na França do leste - ele é, por excelência, o livro escolar do iniciante e, frequentemente, o único livro que ele possui. É verdade que ele oferece em um mesmo conjunto os instrumentos da primeira alfabetização e os textos essenciais da liturgia católica".

${ }^{10}$ É preciso observar que em 1924, data da publicação de Carta de ABC, a obra do autor já era de domínio público, uma vez que ele morreu em 1853.

${ }^{11}$ Sobre a trajetória de José Augusto Bezerra de Medeiros e sua defesa da educação popular ver Oliveira (2017).

${ }^{12}$ Mesmo que para o caso específico de Pelotas, ela fosse considerada uma "cidade letrada" (ver para isso, entre outros, os estudos de Peres, 1995 e Gonçalves, 2010), não se pode negligenciar as altas taxas de analfabetismo no período (final do século XIX e primeiras décadas do século XX) para entender o fenômeno da publicação de Carta de ABC.

${ }^{13}$ Segundo Ferraro e Kreidlow (2004, pp. 183-184), para o caso gaúcho essas taxas e a queda se explicam pelas seguintes condições: "a) a imigração de populações européias, principalmente alemã, a partir de 1824, as quais se distinguiam por alto índice de alfabetização e que contribuíram muito para a duplicação da população gaúcha entre 1872 e 1890; b) a incorporação econômica e social dos imigrantes através do sistema dito colonial ou de pequena propriedade familiar, ao contrário da incorporação através do trabalho assalariado nos cafezais de São Paulo e

\begin{tabular}{l|l|l|l|l|l} 
(C) Rev. HISTEDBR On-line & Campinas, SP & v.20 & $1-20$ & $\mathrm{e} 020029$ & 2020 \\
\hline
\end{tabular}


Estados. vizinhos; c) os fortes vínculos culturais com a Bacia do Prata, especialmente com a cidade de Buenos Aires, a capital da Argentina, País que já se distinguia por uma política educacional mais decidida".

${ }^{14}$ Para o caso das taxas do país há, no período dos Censos de 1872/1890 e o Censo de 1920, "uma redução de 11 pontos percentuais na taxa de analfabetismo para o Brasil como um todo (de $82,3 \%$ em 1872 e $82,6 \%$ em 1890 para 71,2\% em 1920). É, pois, no período 1890 a 1920 que tem início a tendência secular de queda do analfabetismo no Brasil" (FERRARO e KREIDLOW, 2004, p. 185). Além disso, "de 1920 a 1960 acelera-se a queda do analfabetismo. Para o conjunto do País, a taxa cai, no período, de 71,2\% para 46,7\% entre as pessoas de 5 anos ou mais, uma redução de 24,5 pontos percentuais" (FERRARO e KREIDLOW, 2004, p. 186).

15 Frade (2010, p. 276) relembra que esses materiais tinham estrutura previsível, conteúdo permanente e procedimentos de uso tipificados, podendo assim favorecer "tanto uma transmissão da leitura fora da escola como o autodidatismo". 